\title{
The Impact of Knowledge Management on Service Quality: The Mediating Role of Organization Learning (Applied Study: Alexandria Water Company)
}

\author{
Mohamed Ahmed Aly Saied, Mohammed Wahba, Alaa Abdel-Wahed Abdel-Bary, \\ Abdel-Nasser Ghanem
}

Arab Academy for Science and Technology, Cairo, Egypt

Email: mohmedsaied909@gmail.com

How to cite this paper: Saied, M.A.A., Wahba, M., Abdel-Bary, A.A.-W. and Ghanem, A.-N. (2021) The Impact of Knowledge Management on Service Quality: The Mediating Role of Organization Learning (Applied Study: Alexandria Water Company). Open Access Library Journal, 8: e7683.

https://doi.org/10.4236/oalib.1107683

Received: June 23, 2021

Accepted: July 26, 2021

Published: July 29, 2021

Copyright () 2021 by author(s) and Open Access Library Inc.

This work is licensed under the Creative Commons Attribution International License (CC BY 4.0).

http://creativecommons.org/licenses/by/4.0/

\begin{abstract}
The purpose of paper is to explore the role of the learning organization as a mediating variable between knowledge management and service quality in these organizations, also the paper aims to review the concept of learning organization, and the different elements of knowledge management and service quality in service business organizations. In order to achieve the purposes of the study, researcher adopted a descriptive analytical method, valid research instrument was utilized to conduct a survey of (450) questionnaires which were distributed, and (398) questionnaires were retrieved for analysis, rating (88\%) of the distributed questionnaires. Analyzing data was conducted using a set of statistical methods including a normality test along with Cronbach's alpha, standard deviation, confirmatory factor analysis, exploratory factor analysis, multiple and simple linear regression using SPSS-V25 and AMOS-V25. The study reached a set of results, the most important of which are: 1) There is a statistically impact at significant level $(\alpha \leq 0.05)$ of knowledge management on service quality through the learning organization as a mediating variable in Alexandria Water Company in Egypt. 2) There is a significant correlation between learning organization and knowledge management, also there is a significant correlation between knowledge management and service quality, and finally there is a significant correlation between learning organization and service quality. The study reached a set of recommendations, the most important of which are: 1) It is necessary to plan, organize, lead and monitor enterprise knowledge and process management with emphasis on efficiency and effectiveness of the right of access to it; 2) Managers and owners should pay attention to the learning organization, as it plays a major role in building and forming organization culture and knowledge structure of organizations.
\end{abstract}




\section{Subject Areas}

Business and Economics Education

\section{Keywords}

Learning Organization, Knowledge Management, Service Quality

\section{Introduction}

As a result of technical progress, the information revolution and the explosion of knowledge, organizations of all kinds live now in an environment characterized by continuous change (Zahidul \& Rahman, 2019) [1]. As technological changes are in a fast manner, it becomes more difficult to predict the future developments and plan for the future changes, organization has to adapt and make changes in a very limited time (Nouri et al., 2017) [2].

Organizational development has become inevitable in order to adapt to those changes, which prompted organizations to reconsider the provision of services by keeping pace with developments in the environment and searching for Modern management strategies and directions that enable it to adapt to changes in the surrounding environment (Angelos and Panagiotis, 2013) [3].

The increasing intensity of competition among organizations has led organizations to look for ways to have excellent and competitive advantage. Knowledge management and organizational learning tools to gain competitive advantage for different organizations are considered (Alsabbagh and AL Khalil, 2017) [4].

Successful organizations are learning organizations. Learning organization is an organization skilled at creating, acquiring, and transferring knowledge, and at modifying its behavior to reflect new knowledge and insights (Bratianu, 2018) [5]. Learning organizations only can make improvements and they never become stagnant. Although organizations are learning and adapt to change, they are so slow in making changes. Successful organizations consider change and development as the most important factor which determines their success (Al Ahmar, 2014) [6].

In this intellectual age, knowledge has become a very important factor behind the success of organizations. But ineffectiveness managing of the knowledge may cause to be not existing ( $\mathrm{Yu}, 2010)$ [7]. Thus, organizations are looking for efficient knowledge management and organizational learning practices and tools in order to adapt quickly to those changes from inner and outer perspectives, satisfy continuously change business customers' knowledge demand, improve their sustainable organizational performance, and seek local and global spread (Kordab et al., 2020) [8].

Knowledge management can optimize intellectual assets to create value, increase productivity, and gain and sustain competitive advantage (Yang, 2011) [9] 
Knowledge management can be defined as the process of creating, applying and assimilating, organizational knowledge to exploit new opportunities and enhance organizational performance (Alsabbagh and AL Khalil, 2017) [4].

There are many benefits of adopting organizational learning and knowledge management then solving organizational problems is the following: enhancing service quality, provide value-added services, greater productivity of human capital, prevent errors, reduce duplication, increase customer satisfaction, saving time, and stimulate creativity and innovation, creating a close relationship with customers. (Petri and Jussi, 2008) [10].

In the past few decades, practitioners and researchers directed a lot of attention to service quality due to its strong effect on customer satisfaction, customer loyalty, business performance and profitability.

Service quality plays a critical role in achieving a firm's competitive advantage (Roberts et al., 2003) [11] and affects significantly relationship quality with the customer and customer loyalty (Abdel-Rahman, 2012) [12] Service quality has a positive effect on customer loyalty to the organization, which leads to increased organizational income.

Service quality can be defined as a measure of how well the delivered services level matches customer's expectations (Santos, 2017) [13]. Where the consumer compares his expectations with the service he perceives he has received.

Many organizations in general, and Alexandria Drinking Water Company in particular, seek to improve the quality of service provided to their customers, by building a knowledge base that can transform into learning organization. Accordingly, this study seeks to test the impact of knowledge management on the service quality of Alexandria Water Company employees, through learning organization as a mediating variable.

\section{Research Design}

\subsection{Objectives of the Research}

The objectives of the research are:

1) Reviewing the concept of learning organization, identifying learning organization dimensions, and recognition the difference between Learning Organization and Organizational Learning.

2) Identify the ways in which knowledge management process can be relevant to attain the goals of learning organization.

3) Exploring the role of the learning organization as a mediating variable between knowledge management and service quality in service or business organizations in general, and the Alexandria Water Company in Egypt in particular.

4) Reaching out to a set of recommendations that, if implemented, are expected to lead to the improvement and development of organizations service quality.

5) Discuss the characteristics of a learning organization and how to transform into a learning organization, in addition to identifying models of learning or- 
ganizations.

\subsection{Research Questions}

Is there a statistical relationship with a significant impact between knowledge management and the service quality of this type of service organization?

Do human resource management policies affect the learning organization of Alexandria Water Company?

Does the learning organization affect the service quality of Alexandria Water Company employees?

Is there an impact of knowledge management on service quality through the learning organization as a mediating variable?

\subsection{Research Model}

Figure 1 shows the research model of this study.

\subsection{Research Hypothesis}

In order to try to answer the research questions, According to literature review and previous studies,

The following hypotheses were developed to decide if there is a significant impact knowledge management on learning organization:

- There is a statistically significant effect of knowledge management on learning organization.

- There is a statistically significant effect of knowledge management on service quality.

- There is a statistically significant effect of the learning organization on service quality.

- There is a statistically significant effect of knowledge management on service quality through the learning organization as a mediator variable.

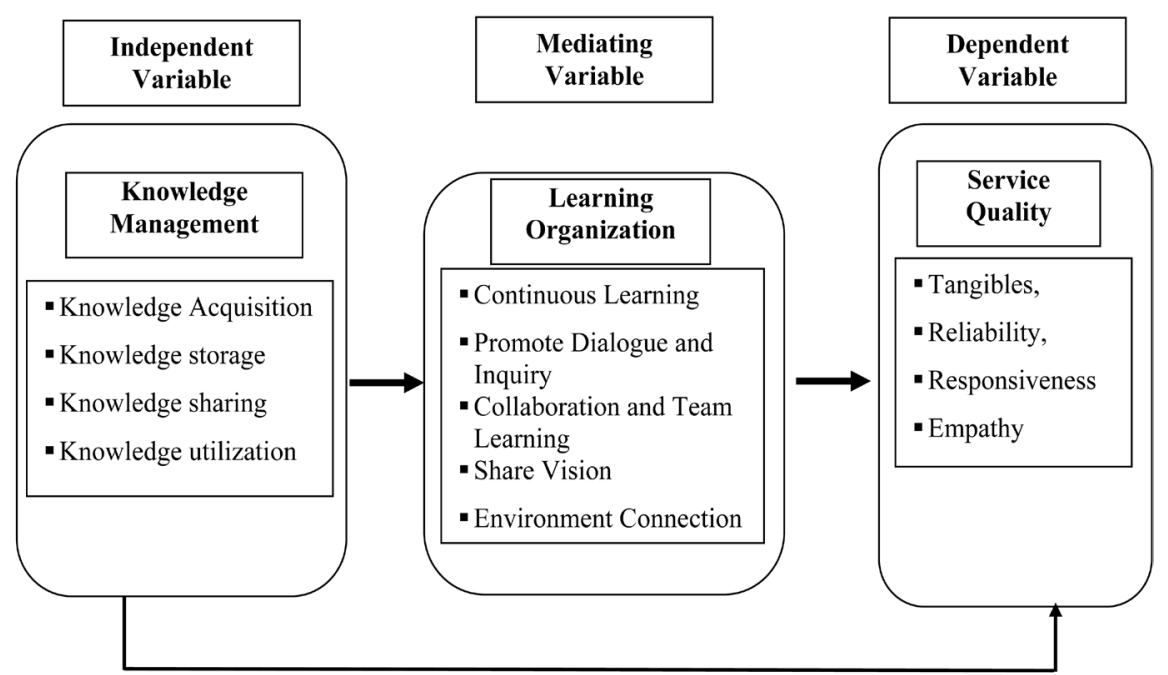

Figure 1. Research model of this study. 


\section{Research Methodology}

The study adopted a descriptive analytical method, the questionnaire was study's main tool for collecting data; where (450) questionnaires were distributed, and (398) questionnaires were retrieved for analysis, the rate was (88\%) of the distributed questionnaires. Analyzing data was conducted using a set of statistical methods including a normality test, along with Cronbach's alpha, means, standard deviation, confirmatory factor analysis, exploratory factor analysis, multiple and simple linear regression using SPSS-V25 and AMOS-V25.

\subsection{Study Tool}

The study of data collected through questionnaires has four sources: knowledge management, learning organization, service quality and basic respondent demographic data.

The 20-item scale of knowledge management section is based on (Sankoka, 2014) [14], and (Al-kaledy, 2012) [15]. There were 5 items measuring knowledge Acquisition, 5 items measuring knowledge storage, 5 items measuring knowledge sharing, and 5 items measuring knowledge utilization.

The 35-item scale of learning organization section is based on (Al-Busaidi, 2018) [16] and (Abd-Elrahman, 2020) [17]. There were 7 items measuring continuous learning, 7 items measuring promote dialogue and Inquiry, 8 items measuring Collaboration and team learning, 6 items measuring share vision, and 7 items measuring environment connection.

The 21-item scale of service quality section is based on (Al-kaledy, 2012) [15]. There were 5 items measuring tangibles, 6 items measuring reliability, 4 items measuring responsiveness, and 6 items measuring empathy.

Responses to all items scales were anchored on a five (5) point Likert scale for each statement which ranges from (5) "full agreement", (4) for "agree", (3) for "neutral", (2) for "disagree", and (1) for "full disagreement."

A questionnaire was prepared on "the impact of the learning organization as a mediating variable between knowledge management and service quality" applied study Alexandria water company in Egypt.

The questionnaire consists of:

1) Part 1: personal data.

2) Part Two: variables dimensions and items.

Table 1 shows the sources of the questionnaire items and number of items, that were developed from previous studies.

Description of the demographic characteristics of the study sample:

The demographic characteristics of the study sample members were analyzed in terms of (gender, age, marital status, academic qualification, practical experience in the current job, administrative level) and the results were as follows:

\section{Gender:}

Table 2 shows the numbers and percentages of the sample members in terms of gender as follows. 
Table 1. Questionnaire items.

\begin{tabular}{|c|c|c|c|}
\hline Variable & $\begin{array}{l}\text { No of } \\
\text { Item }\end{array}$ & $\begin{array}{l}\text { Item } \\
\text { Range }\end{array}$ & Source \\
\hline $\begin{array}{l}\text { Independent Variable: } \\
\text { Knowledge Management }\end{array}$ & 20 & & \multirow{5}{*}{$\begin{array}{l}\text { (Sankoka, 2014) [14] } \\
\text { (Al-kaledy, 2012) [15] }\end{array}$} \\
\hline Knowledge Acquisition & 5 & $1-5$ & \\
\hline Knowledge storage & 5 & $6-10$ & \\
\hline Knowledge sharing & 5 & $11-15$ & \\
\hline Knowledge utilization & 5 & $16-20$ & \\
\hline $\begin{array}{l}\text { Mediating Variable: } \\
\text { Learning Organization }\end{array}$ & 35 & & \multirow{6}{*}{$\begin{array}{c}\text { (Al-Busaidi, 2018) [16] } \\
\text { (Abd-Elrahman, 2020) [17] }\end{array}$} \\
\hline Continuous Learning & 7 & $21-27$ & \\
\hline Promote Dialogue and Inquiry & 7 & $28-34$ & \\
\hline Collaboration and Team Learning & 8 & $35-42$ & \\
\hline Share Vision & 6 & $43-48$ & \\
\hline Environment Connection & 7 & $49-55$ & \\
\hline $\begin{array}{l}\text { Dependent Variable: } \\
\text { Service Quality }\end{array}$ & 21 & & \multirow{5}{*}{ (Al-kaledy, 2012) [15] } \\
\hline Tangibles & 5 & $56-60$ & \\
\hline Reliability & 6 & $61-66$ & \\
\hline Responsiveness & 4 & $67-70$ & \\
\hline Empathy & 6 & $71-76$ & \\
\hline
\end{tabular}

Table 2. Gender.

\begin{tabular}{ccc}
\hline Item & No & Per \\
\hline Male & 256 & $64 \%$ \\
Female & 142 & $36 \%$ \\
& 398 & $100 \%$ \\
\hline
\end{tabular}

The number of males (256) from all study sample numbers (64\%), while the number of females is (142), (36\%).

Age:

Table 3 shows the numbers and percentages of the sample members in terms of the age groups of the study sample members as follows.

The number of individuals in the age group (more than 40 and less than 50 years old) is the largest segment of the study sample, a total number of (204) individuals, at a rate of (51\%), they represent more than half of the study sample, while the age group segment (greater than 50 years), the lowest age group, with a total number of (31) members of the study sample, at a rate of (8\%).

Number of years of experience in the company:

Table 4 shows the numbers and percentages of sample members in terms of number of years of work and experience in the company as follows: 
Table 3. Age groups.

\begin{tabular}{ccc}
\hline Item & No & Per \\
\hline Under 30 years old & 48 & $12 \%$ \\
Over 30 and under 40 years old & 115 & $29 \%$ \\
Over 40 and less than 50 years old & 204 & $51 \%$ \\
Over 50 years old & 31 & $8 \%$ \\
& 398 & $100 \%$ \\
\hline
\end{tabular}

Table 4. Years of work and experience in the company.

\begin{tabular}{ccc}
\hline Item & No & Per \\
\hline Less than 5 Years & 25 & $6 \%$ \\
Over 5 and less than 10 years & 41 & $10 \%$ \\
Over 10 and less than 15 years & 170 & $44 \%$ \\
Over 15 and less than 20 years & 142 & $35 \%$ \\
More than 20 Years & 20 & $5 \%$ \\
& 398 & $100 \%$ \\
\hline
\end{tabular}

Before administering questionnaires, it was necessary to first evaluate the reliability and validity of the instruments. Therefore, this research used Cronbach Coefficient alpha to statistically check the items reliability. And to evaluating the validity of a measurement instrument evaluated content validity, criterion related validity, and construct validity.

\subsection{Pilot Study}

In order to testing questionnaire validity and reliability, the researcher distributed a survey sample of (35) questionnaires.

The reliability of the study questionnaire was verified by Cronbach's Alpha coefficient, and the results showed the Cronbach Alpha coefficient (0.987) which is a statistically acceptable level as long as it is greater than (0.7).

\section{Hypothesis Testing Results}

\subsection{First Main Hypothesis Test}

To test the first main hypothesis, the null hypothesis was developed which is that there is no significant statistical effect of knowledge management of Alexandria Water Company on the learning organization, and to verify the validity of the hypothesis, the simple regression test was used between knowledge management as an independent variable, and the learning organization is a dependent variable, Table 5 shows the results as follows:

It is evident from Table 5 that the statistical value $(T)$ is (18.39) with a statistical significance level less than 5\% ( $\mathrm{p} \leq 0.05)$, we reject the null hypothesis, 
Table 5. Simple regression analysis results for knowledge management and learning organization.

\begin{tabular}{cccc}
\hline & $B$ & $T$ & Sig \\
\hline Constant & 0.738 & 4.704 & 0.000 \\
knowledge management & 0.805 & 18.398 & 0.000 \\
\hline
\end{tabular}

which indicates that there is a statistically significant impact of knowledge management on the learning organization, and accordingly we conclude that there is a statistically significance of knowledge management on the learning organization.

Regression equation is:

$$
y=\propto+B x
$$

learning organization $=0.738+0.805$ knowledge management.

\subsection{Sub-Hypotheses Test for the First Main Hypothesis}

To test the sub-hypotheses, the null hypothesis was developed that is represented by the absence of a statistically significant impact from the dimensions of knowledge management (knowledge acquisition, knowledge storage, Knowledge sharing, knowledge utilization) on the learning organization, and to verify the validity of the hypothesis, the multiple regression test was used between the dimensions of knowledge management (knowledge acquisition, knowledge storage, knowledge sharing, knowledge utilization) as independent variables and learning organization as a dependent variable, Table 6 shows the results as follows.

According to Table 6 it becomes clear that the statistical value $(T)$ of the dimensions of knowledge management (knowledge acquisition, knowledge storage, knowledge sharing, knowledge utilization) amounted to (13.01, 2.42, 2.38, $-1.24)$, respectively, with a level of statistical significance less than $5 \%$. Amounted to $(0.000,0.016,0.04,0.216)$ It is evident that there is a statistically significant effect from first three dimensions of knowledge management (knowledge acquisition, knowledge storage) on the learning organization as all values of the significance level coefficients (Sig) are less than 0.05, but the fourth dimension (Knowledge sharing) is not significant (more than 5\%) which indicates the presence of a significant effect.

Regression equation is:

$$
y=\propto+B x
$$

learning organization $=0.7+0.621 X_{1}+0.124 X_{2}+0.165 X_{3}-0.075 X_{4}$ where,

$$
\begin{aligned}
& X_{1}=\text { knowledge acquisition } \\
& X_{2}=\text { knowledge storage } \\
& X_{3}=\text { knowledge sharing } \\
& X_{4}=\text { knowledge utilization }
\end{aligned}
$$


Table 6. Multiple regression analysis results for knowledge management dimensions and learning organization.

\begin{tabular}{ccccc}
\hline knowledge management Dimensions & $\boldsymbol{B}$ & Beta & $\boldsymbol{T}$ & Sig \\
\hline Constant & 0.7 & & 3.716 & 0.000 \\
Knowledge Acquisition & 0.621 & 0.655 & 13.011 & 0.000 \\
Knowledge storage & 0.165 & 0.122 & 2.426 & 0.016 \\
Knowledge sharing & 0.124 & 0.119 & 2.388 & 0.040 \\
Knowledge utilization & -0.075 & -0.084 & -1.24 & 0.216 \\
\hline
\end{tabular}

\subsection{Second Main Hypothesis Test}

To test the second main hypothesis, the null hypothesis was developed which is that there is no significant statistical effect of knowledge management on the service quality of Alexandria drinking water company.

Table 7 shows the results as follows:

Regression equation is:

$$
y=\propto+B X
$$

service quality $=0.609+0.810$ knowledge management.

It is evident from Table 4 that the statistical value $(T)$ is (21.06) with a statistical significance level less than $5 \%$, which indicates that there is a statistically significance impact of knowledge management on service quality.

\subsection{Sub-Hypotheses Test for the Second Main Hypothesis}

To test the sub-hypotheses, the null hypothesis was developed that is represented by the absence of a statistically significant impact from the dimensions of knowledge management (knowledge acquisition, knowledge storage, Knowledge sharing, knowledge utilization) on the learning organization, and to verify the validity of the hypothesis, the multiple regression test was used between the dimensions of knowledge management (knowledge acquisition, knowledge storage, knowledge sharing, knowledge utilization) as independent variables and learning organization as a dependent variable, Table 8 shows the results as follows:

According to Table 8 it becomes clear that the statistical value $(T)$ of the dimensions of knowledge management (knowledge acquisition, knowledge storage, knowledge sharing, knowledge utilization) amounted to (9.74, 0.384, 1.76, 3.717 ), respectively, with a level of statistical significance less than $5 \%$. Amounted to $(0.000,0.703,0.0 .78,0.000)$ It is evident that there is a statistically significant effect two dimensions of knowledge management (knowledge acquisition, knowledge utilization) on service quality as all values of the significance level coefficients (Sig) are less than 0.05, but the two other dimension (knowledge storage, knowledge sharing) are not significant (more than 5\%) which indicates the presence of a significant effect.

Regression equation is: 
Table 7. Simple regression analysis results for knowledge management and service quality.

\begin{tabular}{cccc}
\hline & $B$ & $T$ & Sig \\
\hline Constant & 0.609 & 4.412 & 0.000 \\
knowledge management & 0.810 & 21.060 & 0.000
\end{tabular}

Table 8. Multiple regression Analysis results for knowledge management dimensions and service quality.

\begin{tabular}{ccccc}
\hline knowledge management Dimensions & $\boldsymbol{B}$ & Beta & $\boldsymbol{T}$ & Sig \\
\hline Constant & 0.892 & & 5.223 & 0.000 \\
Knowledge Acquisition & 0.422 & 0.474 & 9.743 & 0.000 \\
Knowledge storage & 0.023 & 0.019 & 0.384 & 0.703 \\
Knowledge sharing & 0.097 & 0.100 & 1.769 & 0.078 \\
Knowledge utilization & 0.204 & 0.243 & 3.717 & 0.000 \\
\hline
\end{tabular}

$$
y=\propto+B X
$$

service quality $=0.892+0.422 X_{1}+0.023 X_{2}+0.097 X_{3}+0.224 X_{4}$

where,

$$
\begin{aligned}
& X_{1}=\text { knowledge acquisition } \\
& X_{2}=\text { knowledge storage } \\
& X_{3}=\text { knowledge sharing } \\
& X_{4}=\text { knowledge utilization. }
\end{aligned}
$$

\subsection{Third Main Hypothesis}

To test the third main hypothesis, the null hypothesis was developed, which is the absence of a statistically significant relationship between knowledge management and service quality through the learning organization as a mediating variable.

And to verify the validity of the hypothesis and study the extent of a complete or partial relationship, the Path Analysis test was used, using the Amos 26 program and Figure 2 shows the results:

Table 9 illustrate that:

1) Observed Exogenous Variables: The independent variable includes knowledge management.

2) Observed Endogenous Variables: The dependent variable includes service quality, and the mediating variable includes the learning organization.

3) Unobserved Exogenous Variables: Measurement errors of the dimensions of the dependent variable include service quality, and the mediating variable, learning organization.

From the previous table and figure, it is clear that at a level of significance 0.05 , there is a statistically significant effect of knowledge management path on the learning organization with a factor of 0.81 , and the learning organization 


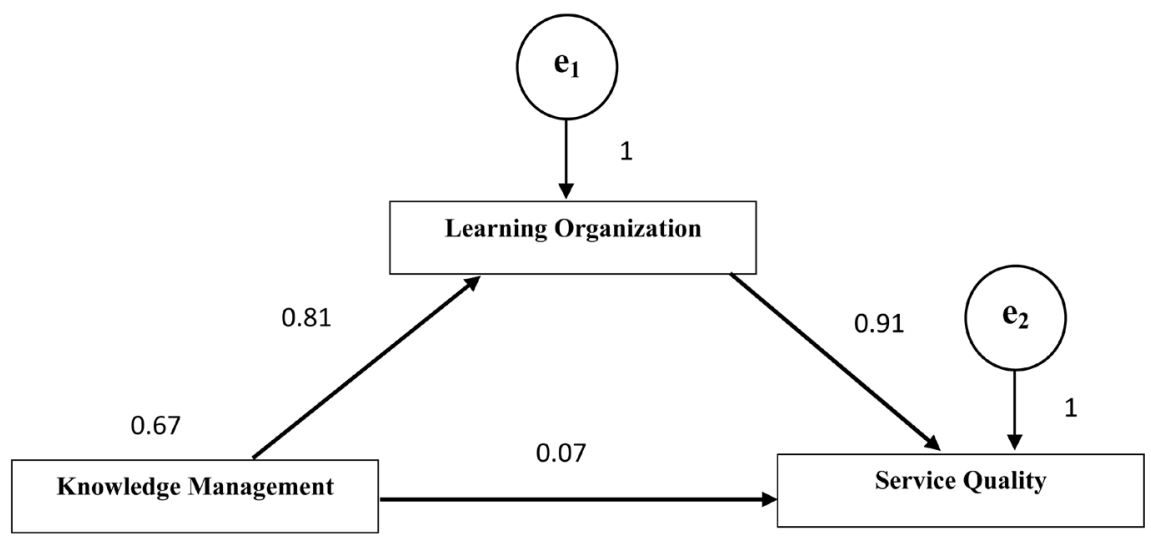

Figure 2. Mediator path.

Table 9. Variables path estimates.

\begin{tabular}{cccccc}
\hline Path & Estimate & S.E & C.R & Sig value & Sig \\
\hline Knowledge Management $\rightarrow$ Learning organization & 0.81 & 0.038 & 21.087 & 0.000 & Sig \\
Learning organization $\rightarrow$ Service Quality & 0.905 & 0.035 & 26.187 & 0.000 & Insig \\
Service Quality $\rightarrow$ learning organization & 0.072 & 0.039 & 1.86 & 0.063 & Insig \\
\hline
\end{tabular}

Path on service quality with an impact factor of 0.91 , as the value of the level of significance for both path are 0.000 , which is less than 0.05 While there is no statistically significant impact of the knowledge management path on service quality, as the value of the level of significance is equivalent to 0.07 , (greater than 0.05).

Table 10 shows the following:

Chi-square (X2): tests the null hypothesis of this test is, the model fits the model is better when it has a small value, whereas this model value is 0.000 , model is fit.

Goodness of Fit Index (GFI): purpose of computing GFI in the case of maximum likelihood estimation, GFI is less than or equal to 1 . Whereas model (GFI) amounted 1 , it indicates a perfect fit.

The Comparative Fit Index (CFI): parameter estimate for the model being evaluated; CFI is truncated to fall in the range from 0 to 1 . CFI values close to 1 indicate a very good fit. Whereas this model value is 1 , model is fit.

The square root of the mean squares of remainder (RMR): It is an indicator of the estimated amount, and the model is better when it has a small value, whereas this model value is 1 , model is fit.

Root Mean Square Error of Approximation (RMSEA): Independent model value is 0.888 , the value of the RMSEA of about 0.05 or less would indicate a close fit of the model in relation to the degrees of freedom, but for the independent model, it accepted according to Independent model.

Based on the previous results and after checking the model test and all the criteria for judging model goodness, and accordingly, the relationship to the mediating variable, which is the learning organization, is a holistic relationship 
Table 10. Model fit index.

\begin{tabular}{cc}
\hline Item & Index \\
\hline Chi Square & 0 \\
The Comparative Fit Index (CFI) & 1 \\
Goodness of Fit Index (GFI) & 1 \\
Root Mean Square Residual (RMR) & 0.000 \\
Root Mean Square Error of Approximation (RMSE) & 0.888 \\
\hline
\end{tabular}

and not a partial one, as there is no significance for the relationship between knowledge management on the service quality of the existence of the learning organization, which means that the learning organization is a necessary condition for the impact of knowledge management on service quality.

\section{Results}

- There is a statistically significant impact of knowledge management on the learning organization.

- There is a statistically significant impact of the dimensions of knowledge management (knowledge acquisition, knowledge storage, knowledge sharing, knowledge utilization) on the learning organization.

- There is a statistically significant impact of knowledge management on service quality,

- There is a statistically significant impact of knowledge management on service quality through the learning organization as a mediator variable, and the holistic impact of learning organization, which means that it will be no significant effect of knowledge management on the service quality without learning organization, which means the learning organization is a necessary condition in order to have an effect of knowledge management on service quality.

\section{Recommendations}

- In today's global, to succeed, organization managers need to improve and enhance the levels of their services quality, because sustainable and competitive advantages are rooted in satisfying customers' needs, wants and expectations.

- The practice of effective learning organization can improve the service quality of the organizations and their employees' jab satisfaction.

- Organizations should pay greater attention to the development and preservation of internal skills and capabilities through the process of learning and sharing knowledge among individuals.

- Managers and owners should pay attention to the learning organization, as it plays a major role in building and forming organization culture and knowledge structure of organizations. 
- It is necessary to plan, organize, lead and monitor enterprise knowledge and process management with emphasis on efficiency and effectiveness of the right of access to it.

- Organizations should adopt learning organization concept and usage of knowledge management processes which may enhance the acquisition of knowledge and growth of learning.

- There should be more empirical evidences in the future to develop the integrated model of learning organization, knowledge management and organizational learning, particularly, in terms of the relationship between the organizational learning success model, knowledge management process of sharing and documenting tacit knowledge and the learning capacity of business organizations.

- Knowledge has become the most important strategic resource in the knowledge age.

- Organizational learning is essentially an important tool to help individuals, groups and knowledge community to share, apply and generate new knowledge.

- The role of knowledge management in organizational learning can strengthen the learning effectiveness of the learning organization and the integration of organizational learning information systems and knowledge management technologies can enhance the knowledge performance and innovation of organizations.

- Organizations should applying mechanics of rewards from which staff to teach them new things, and to promote confidence building among staff, allowing operations knowledge sharing and the development of concepts of cognitive diverse operational productivity and to achieve competence and flexibility in the implementation of the business and as quality of performance.

- Therefore, there should be more literature and empirical evidences in the future to develop the integrated model of organizational learning, knowledge management, learning organization and earning organization which can help to create the value driven organizational learning model.

\section{Conclusions}

This research study attempted to explore the impact of knowledge management and learning organization on enhancing organizational service quality. In order to achieve the purpose of the study, a survey has been distributed on a sample of employees of Alexandria for water company. Findings revealed that there is a statistical impact of knowledge management and the learning organization on service quality in Alexandria Water Company in Egypt.

After conducting the analysis, it can be concluded that learning organization has some impact on the performance of organizations and employees' job satisfaction. Organizations that are practicing learning organization, achieve better performance and employee job satisfaction. They have great chance to flourish 
and develop organizational excellence by practicing effective learning organization.

To meet growing competition in the modern era, organizations have to ensure the practice of learning organization in all the dimensions as these propel the performance of organizations. The employees and managers will get more opportunities to explore themselves if learning culture prevails in the organization. So, for the betterment of the organizations, it has become necessary to have effective learning culture in all organizations.

\section{Conflicts of Interest}

The authors declare no conflicts of interest.

\section{References}

[1] Karim, Z. and Rahman, M. (2019) The Impact of Learning Organization on the Performance of Organizations and Job Satisfaction of Employees: An Empirical Study on Some Public and Private Universities in Bangladesh. https://www.researchgate.net/publication/331481327

[2] Nouri, B.A., Ghorbani, R. and Soltani, M. (2017) The Effect of Knowledge Management on Organizational Innovation with the Mediating Role of Organizational Learning (Case Study: Agricultural Bank in Iran). Journal of Applied Economics and Business Research, 7, 194-211.

[3] Pantouvakis, A. and Mpogiatzidis, P. (2013) The Impact of Internal Service Quality and Learning Organization on Clinical Leaders' Job Satisfaction in Hospital Care Services. Leadership in Health Services, 26, 34-49. https://doi.org/10.1108/17511871311291714

[4] Alsabbagh, M. and Al Khalil, A.H. (2017) The Impact of Knowledge Management on Organizational Learning (An Empirical Study on the Education Sector in Damascus City). International Journal of Academic Research in Business and Social Sciences, 7, 560-578. https://doi.org/10.6007/IJARBSS/v7-i4/2833

[5] Bratianu, C. (2018) Organizational Learning and the Learning Organization.

[6] Al Ahmar, G.O., Rofiqb, A. and Hadiwidjojoc, D. (2014) The Impact of Knowledge Management, Learning Organization, and Educations Organization on Organization Performance: A Case in Brawijaya University. Asia-Pacific Management and Business Application, 3, 28-47. https://doi.org/10.21776/ub.apmba.2014.003.01.3

[7] Yu, Y. (2010) Exploring the Relationships of Knowledge Management, Organizational Innovation and Financial Performance. IEEE International Conference on the Advanced Management Science (ICAMS), Chengdu, 9-11 July 2010.

[8] Kordab, M., Raudeliuniene, J. and Meidute-Kavaliauskien, I. (2020) Mediating Role of Knowledge Management in the Relationship between Organizational Learning and Sustainable Organizational Performance. Sustainability, 12, 10061.

[9] Yang, D. (2011) The Effect of Knowledge Management on Product Innovation-Evidence from the Chinese Software Outsourcing Vendors. iBusiness, 3, 16-22. https://doi.org/10.4236/ib.2011.31003

[10] Paajanen, P. and Kantola, J. (2008) Applying Systems Thinking in the Evaluation of Organizational Learning and Knowledge Creation.

[11] Grant, R.M. (2003). Toward a Knowledge-Based Theory of the Firm. Strategic Management Journal, 17, 109-122. https://doi.org/10.1002/smj.4250171110 
[12] Abd-Elrahman, A.H. (2012) Measuring Service Quality and Its Impact on Relationship Quality with the Customers and Their Loyalty to the Organization. Master thesis, Productivity and Quality Institute, The Arab Academy for Science \& Technology and Maritime Transport, Cairo.

[13] Coutinho, V., Domingues, A.R., Caeiro, S., Painho, M., Antunes, P., Santos, R., Videira, N., Walker, R.M., Huisingh, D. and Ramos, T.B. (2017) Employee-Driven Sustainability Performance Assessment in Public Organisations. Corporate Social Responsibility and Environmental Management, 25, 29-46. https://doi.org/10.1002/csr.1438

[14] Sankoka, S. (2014) Knowledge Management Processes and Its Role in Existing Organizational Learning, A Case Study of the General Directorate of Algeria Telecom in Constantine West. Faculty of Economics, Commercial Sciences and Management Sciences, Oum El Bouaghi.

[15] Al-kaledy, S. (2018) The Role of Quality Service Dimensions and Organizational Learning Abilities in Developing Culture Excellence (Field Study in Industrial Companies Enlisted at Kuwait Stock Exchange).

[16] Al-Busaidi, S.S. (2018) The Degree of Availability of the Learning Organization Dimensions in Sultan Qaboos College for Teaching Arabic to Non-Native Speakers.

[17] Abd-Elrahman, El-Borsaly, A. and Hassan, S. (2020) The Impact of Service Quality on Organizational Performance in the Mobile Telecommunications Sector in Egypt. Proceedings on Engineering Sciences, 2, 93-104. https://www.pesjournal.net https://doi.org/10.24874/PES02.01.010 